\title{
Indigenidad y cine indígena
}

\section{Indigeneity and Indigenous Film}

\author{
Sokol Keraj (Albania) \\ Institución Universitaria Politécnico Grancolombiano \\ Correo electrónico: skeraj@poligran.edu.co
}

\section{Resumen}

Este artículo explora el cine indígena en general en los "hojaldrados" contextos entre el "ser" y los "devenires" de la indigenidad /desde los movimientos culturales, socioeconómicos, epistemológicos, políticos, históricos, estéticos y cinematográficos) y particularmente el acercamiento emancipatorio transformativo de la $\mathrm{ONG}$ Vídeo nas Aldeias (VNA, 'video en las aldeas'): productora, distribuidora, promotora y escuela de cine indígena en Brasil. VNA reconsidera y redirige el "sí mismo" indígena y el otro "común" en un contexto contemporáneo intercultural, transnacional, resaltando a la vez el contexto particular brasileño como "vital

\section{Abstract}

This article explores indigenous film in general within the layered contexts between indigenous 'being' and 'becoming' (from cultural, socioeconomic, epistemological, political, historical, esthetical, and cinematographic movements); particularly, the transformative emancipating closeness of the ONG Vídeo nas Aldeias (VNA 'Video in the Villages'): a Brazilian producer, distributor, developer, and indigenous film school. VNA reconsiders and redirects the indigenous 'self' and the 'common' other in a contemporary intercultural, transnational context, highlighting, at the same time, the particular Brazilian context as "vital towards the training of a new (demystified) look at the
3 de octubre de 2013

3 de febrero de 2014 5 de marzo de 2014
Para Citar este artículo / to Cite this ARticle

Keraj, S. (2014). Indigenidad y cine indígena. Poliantea, 10(18), pp. 11-32. 
frente a la formación de una nueva (desmitificada) mirada hacia los pueblos indígenas y al deshacer de los prejuicios profundamente enraizados". El cine y el video como formas y modos de conocer, medio (tecnología audiovisual), imagen, arte y operaciones, géneros, procesos sociales, metodologías de producción y sus apropiaciones políiticoculturales pueden ser una herramienta poderosa para despertar conciencia y desafiar el orden de lo sensible en el juego disensual de la semejanza con la otredad.

Palabras clave: indígena, cine, cultura, otredad, igualdad, emancipación, política, estética. indigenous populations and to the deconstruction of deeply rooted prejudices." Film and video as ways of knowing, media (audiovisual technology), image, art and operations, genders, social processes, production methodologies and their politico-cultural appropriations could be a powerful tool to make people conscious and to challenge the sensible order within the dissentive game of otherness similarity.

Keywords: indigenous, film, culture, otherness, equality, emancipation, politics, esthetic. 


\title{
Indigenidad y cine indígena
}

\section{Indigeneity and Indigenous Film}

\author{
Sokol Keraj (Albania)
}

Doctor en Media Studies en la Universidad de Bayreuth, Alemania.

\section{Introducción}

Este artículo ofrece un contrargumento a y desde las tempranas teorías de recepción de medios y subjetivización (media spectatorship and subjectification) formuladas conforme a teorías de ideología, hegemonía cultural e imperialismo tecnológico. Se desafía este entendimiento y mirada monolítica hacia la modernidad y, particularmente, su relación con la indigenidad, abriendo alternativas históricas dentro de esta, que dan paso a una "nueva indigenidad" que busca "deshacer los significantes hegemónicos, afectar su química semántica usual, para producir nuevas valencias, y así reconfigurar la indigenidad en sí abriéndola hacia el reconocimiento de la contemporaneidad histórica" (De la Cadena y Starn, 2007, p. 11) de intervención, desacuerdo, flexibilidad, necesidad, intercambio, compartir y futuro más allá de apropiación declamatoria, resistencia y reconocimiento.

Los medios indígenas se originan desde las primeras "aventuras" de los antropólogos y cineastas etnográficos involucrados en diferentes ONG en la década de 1980 como una respuesta al contexto emergente del activismo indígena para usar y apropiar los medios como herramientas de acción cultural y política.

La reciente evolución y revolución de los medios audiovisuales (disponibilidad de tecnologías, abaratamiento, portabilidad, facilidad para adquirir 
una experticia) son una condición de posibilidad para el cine indígena, sin las cuales no existiría ninguna oportunidad para acceder al cine como un camino para relacionarse con la realidad, inscribir lo propio, una mirada (alternativa) particular y alcanzar a las audiencias locales y globales. Los medios indígenas se han desarrollado y expandido en diferentes partes del mundo: desde los aborígenes en Australia y Nueva Zelanda, los nativos en Canadá y los Estados Unidos, hasta los indígenas en América Latina y los indios en Brasil.

Generalmente, los medios indígenas no obedecen a los procesos convencionales de producción, y el cine indígena (como práctica y discurso particular originado de ellos) se muestra también bastante heterogéneo respecto de métodos, estilos y formatos de producción.

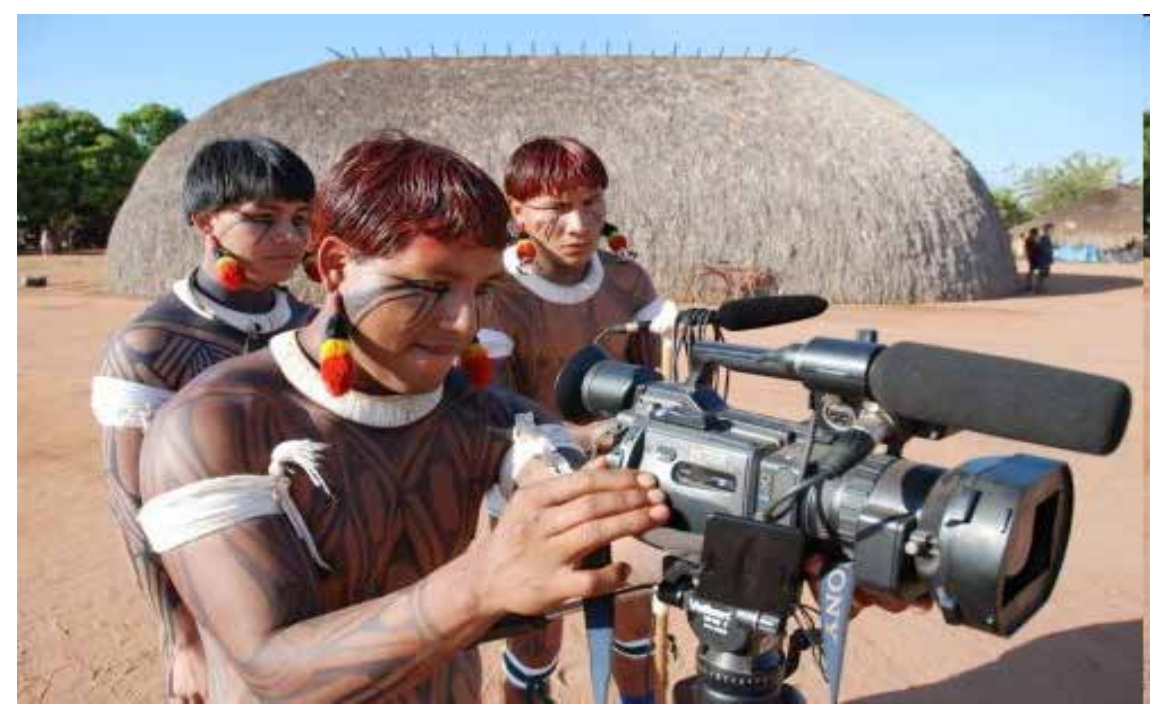

Figura 1. Circulación de imágenes de tecnologías "blancas".

Fuente: La investigación

La circulación de imágenes (figura 1) de tecnologías "blancas" complejas usadas por los indígenas "auténticos" desafía las miradas que equivalen a la autenticidad como pureza de influencias de fuera.
No se puede seguir asociando la tradición con el pasado y lo moderno-tecnológico con el presente en este contexto: “... una modernidad indígena no necesariamente supone la exclusión o reemplazamiento de 
formas tradicionales de conocimiento o maneras de ser en el mundo (ways of being-in-the-world)" (Deger, 2006). El uso de la tecnología no es evidencia de la pérdida de la cultura ni de los indígenas convirtiéndose en blancos (Western) llevando a la deconstrucción del binario entre el pasado y el presente, tradicional y moderno, indígena y blanco (Western).

La naturaleza debatible de este asunto fue evidente en un incidente descrito por Payakan, un activista kayapo de la década de 1980. Un juez brasilero le cuestionó el secreto de este choque:

Juez: Entiendo que sabe cómo operar un VCR [video casette recorder 'videocasetera']. ¿Es esto cierto?

Payakan: Sí, su señoría.

Juez: ¿Cómo puede usted llamarse un indio si trabaja con estas máquinas? Ni siquiera yo sé cómo usar un VCR. ¿Cómo puede ser usted un indio de verdad?

Payakan: Su señoría, la única razón por la cual yo sé cómo operar una VCR es que me tomé el tiempo para aprender (Conklin, 1997, p. 715).

El caso de arriba ejemplifica "las maneras en las cuales las imágenes visuales y las tecnologías visuales atraviesan fronteras que imaginamos a menudo como separadoras de diferentes culturas y clases" (Poole, 1997, p. 5), extendiendo su entendimiento desde nuevas circunstancias, necesidades y sensibilidades.

\section{Indigenidad}

El sobreviviente signo indigenidad todavía prende la imaginación e imaginería de un popurrí de prefijos “inmunizadores" y "profilácticos" (un-, pre-, anti-, de-, pos-: pre-historia, anti-evolución, de-colonización, poscolonización), de "mutación" a través de hibridación o fragmentación (inter-, trans-, multi-) lingüísticamente atrapados en la nostalgia utópica de una humanidad no contaminada, virginal, natural que todavía sobrevive en las esquinas más remotas del planeta en puros paraísos, naturaleza real, peligrosa y salvaje.

A pesar de su "pronosticado" destino a desaparecer después del encuentro con la "historia", a ser aniquilados o absorbidos por sus respectivas sociedades nacionales o por el sistema-mundo emergente, modernizante, los pueblos indígenas siguen existiendo $y$, contrariamente a las expectativas, se han convertido en una fuerza en el mundo contemporáneo, revirtiendo las asíllamadas narrativas 
de "víctimas de progreso" o "detribalización”, que describen los procesos de extinción cultural y física (Miller, 2003). Ellos se han adaptado flexiblemente al "cambio" y "pérdida" cultural, han aprendido las estrategias de la lucha política y ahora están adueñándose del manejo de las técnicas de información de la era digital y estética, para así poder generar apoyo a sus causas (identidad, comunidad, pertenencia y placer) y abrir-se al sensorium social, intercultural, global.

Hoy en día los indígenas representan aproximadamente cinco por ciento de la población mundial ${ }^{1}$ (www.survival-international.org), y sin embargo siguen siendo por lo menos discursivamente "borrados" de la superficie de la Tierra y de la historia.

La concepción de la indigenidad se ha manipulado ahistóricamente para servirles a los intereses coloniales,

\footnotetext{
International Working Group for Indigenous Affairs (IWGIA) indica en su tercera publicación que "there are over 5.000 indigenous groups, with a population of 300 million350million" (IWGIA, 1997a, p. 7). Realmente, es difícil indicar con precisión cuántos indígenas existen en el mundo, sobre todo por cuestiones conceptuales, es decir, qué significa indígena como tal. Se calcula que $80 \%$ de los indígenas vive en Asia, $7 \%$ en Suramérica, $6 \%$ en Norteamérica, $4 \%$ en África, $3 \%$ en Australia-Oceanía y $1 \%$ en Europa (Goehring, 1993). Los pueblos indígenas controlan más de $12 \%$ de la tierra del planeta (Ewen, 1994, citado por Miller, 2003, pp. 1 1-131.
}

estatales (como también a determinados grupos indígenas), a la explotación económica local o globalmente.

Los pueblos indígenas no son "inmunes" y necesariamente "resistentes" a los movimientos, circulaciones e intercambios de discursos, bienes, tecnologías, tiempos, espacios y sentidos de la globalización, los cuales "forzosamente" enlazan o siguen separando a los pueblos del mundo. Los pueblos indígenas todavía oscilan entre "el poder localizador de su [C] ultura y las fuerzas [des-]unificadoras del mundo contemporáneo" (Coates, 2004, p. 15). Más allá de la conceptualización de los pueblos indígenas como contrincantes del espíritu “evolutivo, teológico" de la historia y el progreso, ellos se han ganado un lugar en los productos culturales y en la cultura global, la economía y la política del siglo XXI (De la Cadena y Starn, 2007), interviniendo los mecanismos y las ideologías que han hecho de los indígenas la gente más investigada y representada en el mundo (Alia y Bull, 2005).

Históricamente, la emergencia de la indigenidad coincide con la emergencia de la democracia en Suramérica en los comienzos de la década de 1980, cuando el pluralismo y la identidad cultural (entendida desde el multiculturalismo neoliberal) 
ofrecían un discurso y un lugar más seguro para la supervivencia de la indigenidad frente al deterioro de los movimientos sindicales y la agresividad de los medios transnacionales ${ }^{2}$.

La indigenidad emerge como un ensamblaje de discursos y estrategias consientes enraizadas en el ambiente global de los activistas no indígenas, discursos de derechos humanos, ONG, y organizaciones mundiales, tales como el Forum Permanente de las Naciones Unidas sobre los Asuntos Indígenas (UN Permanent Forum on Indigenous Issues) y las alianzas indígenas transcontinentales (Himpele, 2008, p. 57).

El reconocimiento y la presencia permanente de los pueblos indígenas en la Organización de las Naciones Unidas representan dos momentos cruciales en su lucha histórica para sobrevivir ${ }^{3}$.

2 El comienzo de la década de 1990 encuentra a los pueblos indígenas no reconocidos constitucionalmente en todo el continente, a excepción de Brasil, que en su Constitución de 1988 logra reconocimientos importantes para los pueblos indígenas. Los países que siguieron reformando sus constituciones para reconocer a las comunidades indígenas y sus derechos fueron Colombia, México y Perú.

3 El Foro Permanente para las Cuestiones Indígenas fue establecido para asesorar al Consejo Económico y Social de las Nacio-
La actual "resucitación" de la indigenidad en las políticas nacionales de muchos países en América Latina se materializa con el ceremonialismo performado en las posesiones presidenciales en Colombia, Ecuador y Bolivia, donde Evo Morales fue el primer presidente indígena electo en la historia. En una ocasión, la presidenta argentina Cristina Fernández de Kirchner enfáticamente expresó que por primera vez los presidentes de América Latina tenían los rostros de la gente que representaban. Estos momentos afirman "un sentido extraordinario de posibilidad y esperanza política" (Zamorano, 2009, p. 3) para muchos pueblos indígenas y otros grupos históricamente oprimidos y para el futuro político de las naciones a las que pertenecen" . "Estos grupos se

nes Unidas (Ecosoc), organismos de las $\mathrm{Na}$ ciones Unidas, a los Estados miembros y a los pueblos indígenas de indígenas. El Foro Permanente se ha convertido rápidamente en el "centro de coordinación de las cuestiones indígenas en la $\mathrm{ONU}$ y un lugar de encuentro para los pueblos indígenas, los Estados miembros y otras partes interesadas en el mundo".

4 Las movilizaciones indígenas flexiblemente remodelan sus peticiones para atender las necesidades de la época, que oscilan desde los derechos humanos, reforma de la tierra, educación y políiticas económicas, a la ciudadanía nativa, resistencia antiglobalización o confrontación armada extrema, como en los zapatistas (EZLN, 'Ejército Zapatista de Liberación Nacional') en México (Sturken y Cartwright, 2009). 
han transformado de pobres, olvidados, y virtualmente invisibles, en una fuerza formidable en menos de una generación [cursivas del autor]" (De la Cadena y Starn, 2007, p. 2), mientras tanto "muchas colectividades se encuentran más vulnerables que hace 30 años" (Pratt, 2007, p. 398).

Las nuevas circunstancias históricas invitan a una redefinición de lo indígena desde adentro, dejando atrás la "tradición nativa", "el esencialismo" y el "indio hiperreal" (Ramos, 1998), para superar la categorización por los otros, pero sin excluir al otro (otredad) y buscar una definición trabajable más allá de los entendimientos clásicos de la indigenidad relacionada con el imaginario, la imaginería, las narrativas residuales y las expectativas de un "orientalismo inverso (reverse orientalism)" (Guha, 1989), "un discurso que descarta el entendimiento de la indigenidad como un proceso histórico abierto" (De la Cadena y Starn, 2007, p. 3), una definición que considere la transición de la visibilidad ahistórica de la indigenidad residual hacia la emergencia de una invisibilidad histórica de un nuevo indigenismo, visto desde "una mirada de mezcla, eclecticismo y dinamismo como esencia de indigenidad siendo opuestas al despego o 'la corrupción' de algunos estados originales de pureza [cursivas del autor]" (De la Cadena y Starn, 2007, p. 3).

Historiar la indigenidad flexibilizaría la constancia de las preestablecidas fronteras "naturales" de primacía, cuantía de sangre (blood quantum), posesión de tierra, cultura, autenticidad que principalmente se han originado o generado desde la experiencia colonial europea y que reflejan las narrativas nostálgicas de "falta y pérdida" de estas mismas sociedades.

El devenir de los pueblos indígenas reconoce las "fuerzas históricas que cada vez más atraen a las comunidades indígenas en el contexto global" (Huhndorf, 2009, p. 3). El devenir reconoce la flexibilidad como una ganada capacidad histórica para intervenir la "visibilidad" ahistórica manifestada a través de expectativas, prejuicios y estereotipos y para inscribir la indigenidad desde una presuposición de igualdad en la arena global. Esto desafía material y discursivamente la "invisibilidad" histórica de transformaciones profundas de la agencia indígena en la participación sociopolítica. Así las cosas, el devenir de la indigenidad se convierte en un indicio de subjetivización como alternativa emancipatoria a las "políticas de identidad" y "activismo cultural". 
La identificación requiere una identidad ya existente, la cual es una manera ahistórica de ser y hablar y su respectiva in-visibilidad que es ya posible dentro de un orden existente o dentro de un "campo perceptual" o "mundo sensible" existente. La subjetivización es siempre una "desidentificación, mudanza de la naturalidad de un lugar" (Rancière, 1995, p. 226). La lógica rancièriana de emancipación rompe con los discursos residuales y les ofrece una nueva visibilidad a los pueblos indígenas no simplemente como "criaturas de necesidad, queja y protestas, sino como criaturas de discurso y razón, que son capaces de oponerse a la razón con la razón y que puedan dar a sus acciones una forma demostrativa" (Rancière, 1995, p. 48). La subjetivización es sobre la "apariencia (the coming into presence), sobre cómo algo hace presencia" (Biesta, 2006), de una manera de ser que no tiene ni lugar ni parte en el orden existente de las cosas.
El devenir del así llamado nuevo indigenismo (De la Cadena y Starn, 2007) interviene el orden colonial establecido y, al mismo tiempo, cuestiona el esencialismo, la ahistoricidad y las falsas pretensiones autoasociadas a esto. Estos aspectos hacen un llamado urgente hacia acercamientos y paradigmas cambiantes que pueden captar e inscribir mejor la indigenidad viviente e histórica como un axiomático sujeto "igual" en lugar de uno imaginado y "fascinante".

La aproximación del nuevo indigenismo agranda la esfera del encuentro con la otredad desde la presuposición de igualdad, donde el otro (en el encuentro físico o medial) deviene catalizador emancipador; él causa cuestionamiento, autorreflexión desde su presencia y no desde su intervención. 


\section{Aspectos del cine indígena y su locación ${ }^{5}$}

¿Cuál es el impacto de la agenda indígena contemporánea o del discurso de la indigenidad sobre las autorrepresentaciones indígenas? ${ }^{6}$

La premisa romántica de un "renacimiento del cine" casi un siglo

5 Los estudios y proyectos etiquetados general y ampliamente como "imaginería generada desde lo subjetivo-nativo" o "medios indígenas" tienen en cuenta varios aspectos para definirse:

- La autoría y su naturaleza productiva y creativa desde lo individual, colectivo y colaborativo.

- La autoridad y sus implicaciones en la toma de decisiones, la demostración interna de poder y vulnerabilidad (Aufderheide, 2000) frente a los factores externos determinantes (Armes, 1987).

- Colaboración, activismo y aliados, campañas para levantar fondos, algunas $\bigcirc \mathrm{NG}$.

- La autenticidad o su invención (Conklin, 1997).

- La cosmovisión, entendida como una mirada particular, la visión de lo invisible en un contexto intercultural (Deger, 2006).

- La etnicidad que fortalece la integridad, territorialidad y soberanía de los grupos (Alia y Bull, 2005).

- La cultura como el locus de la historia, memoria, performatividad, estilos de vida (ways of living), encuentros y devenires permanentes (De la Cadena y Starn, 2007)

- La diversidad que abre un espacio para conocer, actuar, diálogo, aceptación en la esfera nacional (Díaz-Polanco, 2000).

- La globalización que permite surgir la identificación a un nivel panindígena con fines comunes de resistencia, reconocimiento y futuro (De la Cadena y Starn, 2007).

6 Para una genealogía de los momentos importantes del surgimiento del video indígena en Latinoamérica, véase Aufderheide (2000), Salazar y Córdova (2008) y Schimy (2009). después de su primera proyección en París, teniendo esta vez como protagonistas a los pueblos indígenas, ha llamado la atención de los estudiosos (y no solo) de todo el mundo. La imagen exótica del indio con su cuerpo pintado, las plumas en su cabeza y los labios perforados llevando sobre su hombro una cámara de video mientras corre en la selva resulta demasiado "irresistible" para la imaginación de un observador cultural lejano.

La seducción de tales imágenes para los consumidores occidentales aún reside en la manera en que ellos visualizan un "choque" entre el cuerpo nativo y las nuevas tecnologías de comunicación [...] el choque entre el imaginado tiempo atemporal, ahistórico de los pueblos indígena, y el tiempo de la posmodernidad representado a través de su ícono, la cámara de video (Schiwy, 2009, p. 2).

Tal imaginería fabrica una indigenidad visible, distinguible y reconocible que usa el cine indígena como una plataforma para performar "políticas de posicionamiento" (Deger, 2006, p. 47), para recordar, permanecer y retener la cultura, la identidad y la tierra, entre otras cosas. Por otro lado, la nueva indigenidad 
emergente comete una "intervención" en el orden de lo sensible, desafía la percepción establecida y cuestiona la naturalidad y obviedad que (disensualmente) atraviesa las ya fijas, vividas y discursivas "categorías del ser" (acá la indigenidad con su etiquetaje desde una determinada visión de la modernidad y su in-visibilidad en las imágenes del cine percibidas por el otro), para separar a ellos de sí mismos asegurando así una visión de devenir. Tal "operación disensual"" (Rancière, 2009, p. 66) (de la separación del sentido del sentido) lleva a nuevas connotaciones y visiones relacionadas con la indigenidad, modernidad, cine y otredad cuando estas están revisadas históricamente, intervenidas políticamente y presenciadas estéticamente.

... nosotros estamos usando el instrumento de video en una forma diferente, a nuestra manera. Lo usamos para que nos ayude a que la sociedad nos comprenda mejor, en la manera que nosotros pensamos, nosotros

7 El disenso (Rancière, 2009) no es una querella o deasacuerdo de intereses u opiniones personales, sino una operación políticoestética que "crea una fisura en el orden de lo sensible por confrontar el marco establecido de la percepción, el pensamiento y la acción con lo 'inadmisible'" [cursivas del autor]. (Rockhill, 2004, p. 85). aquí y ustedes allá. [E]s bueno para nosotros tener este diálogo. Hay gente que dice: "Ah, están tratando de ser blancos". Hoy en día, todo el mundo usa tecnología japonesa, pero el japonés no es brasileño, ni el brasileño japonés. Esto es lo mismo. Yo no soy xavante, soy ashaninka y él es xavante. Pero nosotros nos podemos organizar usando el mismo instrumento que usan los blancos, pero con un fin y una imagen diferente. Lo usas según tus necesidades y la manera como te organizas [...] Y así estamos comenzando a ver qué podríamos y qué no mostrar a los de afuera [...] para que los de afuera nos entiendan mejor y nos respeten más. [T] ú ves el mundo del otro y miras el tuyo. [E]l video puede ayudar a las personas a reflexionar sobre ellos mismos, porque el contacto con el mundo de afuera ha debilitado nuestra tribu, y si no encuentras una manera de reflexionar, de verse valioso, tu cultura se muere. [T]ú inventas la cultura según necesidades, estilo de vida y cambios en el planeta. Y así funciona para nosotros también [...] nuestra cultura cambió (Isaac Pinhata, cineasta y maestro ashaninka). Como la cita de Pinhata demuestra, los pueblos indígenas tienen consciencia de que están ocurriendo más 
cosas en lo que "un cuadro representativo puede exponer, o que un ojo ajeno puede percibir", porque, para poder atrapar de verdad las capas de significados incrustados dentro de la imagen es necesario examinar también las "particularidades de la percepción cultural y las historias" (Deger, 2006, p. XV) del flujo social $\mathrm{y} \mathrm{medial}^{8}$ (Poole, 1997). El cine y los medios han desempeñado un papel significativo en el rompimiento y la conexión (breaching and bridging) de las fronteras culturales a través del intercambio de imágenes, "realidades", materialidades e historias que llevan al intercambio de miradas hacia mundos encontrados a través de la cámara y la pantalla. Un intercambio de imagen de algún modo "precipita las extraordinarias transformaciones materiales y sociales experimentadas

8 La imagen, más que un estado de ser la state of beingl, es un proceso de multiplicidad de devenires singulares, de singulares articulaciones de habla y visibilidad como resultado de diferentes prácticas, estrategias y lógicas de "imágenes". La pregunta "¿qué son las imágenes, qué hacen y qué efectos generan?" (Rancière, 2007) sugiere un acercamiento multinivel al cine y sus imágenes, las cuales deben ser vistas, pensadas y analizadas "acorde con las redes discursivas a las cuales pertenecen, la forma de la presencia visual que emplean y las combinaciones con otras imágenes [internas o externas] explotadas en la producción de ellas" (Tanke, 2011 , p. 122). por los pueblos indígenas" (Deger, 2006, p. XVI).

La sociedad en la declaración de Pinhata no implica solo los factores de presión y decisión en el discurso y la vida indígena, como organizaciones gubernamentales o no gubernamentales, patrocinadores, entidades económicas, simpatizantes, aliados y activistas. La sociedad es también su parte dejerarquizada, "tú y yo", desde la posición ordinaria, común de las cotidianas necesidades, relaciones, contactos, miradas.

La sociedad se extiende en este caso hacia lo "insignificante", lo "invisible" de las mayorías obviadas. Es en la base de la sociedad donde el intercambio de miradas debería producirse, para poder desraizar a los estereotipos y prejuicios desde lo común y lo ordinario del "otro verdadero".

Qué hace interesante tal enfoque sobre las prácticas y los discursos del Video en las aldeas ${ }^{9}$ (parte de la cual

\footnotetext{
9 Vídeo nas aldeias (VNA, video en las aldeas) es un proyecto pionero en la producción audiovisual indígena en Brasil. Desde sus comienzos, el objetivo del proyecto ha sido el apoyo a las luchas de los pueblos indígenas para fortalecer las identidades y las herencias territoriales y culturales, a través de los recursos audiovisuales y la producción compartida con los pueblos indígenas, con los cuales Video en las aldeas trabaja, empleando a la vez una naturaleza particular de este proyecto eman-
} 
son las actividades fílmicas de Pinhata y su pueblo ashaninka) es la pregunta relacionada con las posibilidades políticas y estéticas de la representación indígena en la circulación más amplia de la indigenidad (en lo intercomunal, nacional, regional y global), atrapadas entre las interpretaciones (desde la expectativa, imaginación, seducción mítica etc.), géneros convencionales y los contextos que podrían crear significados rivales que renuevan el interés sobre los vínculos entre medios y políticas, dando nuevas valencias a la política misma y el papel, los usos y el poder (estético, entre otros) de los medios (el cine en este caso) en esta combinación.

Poner la producción de video indígena con el signo de cine habilita una presuposición de igualdad que se atreve a pensar, entrar y desafiar las jerarquías de una experiencia y práctica asociadas hasta el presente con la mirada hegemónica del imperio y el símbolo del capitalismo ${ }^{10}$.

cipador que reconoce la renovación cultural en los devenires de la indigenidad revisados desde la mirada del otro.

10 "El cine y el video han reproducido la mirada del Imperio, reforzando las ideas sobre los pueblos indígenas como habitantes de un mundo primitivo, pretecnológico primeramente ofrecido en las narrativas de la Conquista. Los medios indígenas desafían esta mirada en la pantalla" (Schiwy, 2009, p. 13). Si el cine y los medios audiovisuales han sido
Asociar lo indígena con el cine ofrece al primero la posibilidad histórica de ser parte de una experiencia humana más grande, relacionarlo a un mundo más amplio y no definir la experiencia solo en función de la primacía o el pasado.

El cine indígena (como parte de un contexto más amplio de los medios indígenas) no aparece de la nada, sino en relación con experiencias previas del cine etnográfico o el "cine cometido" en la segunda parte del siglo pasado, transitando suavemente por una práctica transformadora y ruptura discursiva, como una trayectoria diacrónica que conduce a la necesidad de considerar a los medios indígenas como un campo autónomo e independiente de la producción medial distinta del documental no indígena o del cine etnográfico (Salazar y Córdova, 2008, p. 40).

Visto así lo indígena, en el cine indígena no sería solo una etiqueta de apropiación tecnológica desde una "panflética" resistencia y

\footnotetext{
"the ultimate myth-making institutions of the past century" (Nilsson-Julien, 2005, p. 21) es igualmente verdadero que el cine puede ser también empleado para deshacer ese constructo. La flexibilidad atribuida a la nueva indigenidad se acopla a la flexibilidad misma inherente en el cine como tal, el cual está abierto para inscribir cualquier objetivo y visión y ser leído por cualquier mirada.
} 
revitalización cultural. Knopf (2008) con razón pregunta qué quedaría del cine indígena si quitamos justamente esa etiqueta (indígena).

Posicionado en algún lugar entre los mundos de vida (lifeworlds) fenomenológicos de sus vidas diarias y las categorías coloniales a través de las cuales se han constituido, hacer de estos medios parte de un conjunto más amplio de prácticas a través de las cuales [los pueblos indígenas] están reflexionando y transformando las condiciones de sus vidas (Ginsburg, 2003, p. 52).

En este sentido, lo que hace a este cine indígena son sus relaciones fuertes y respuestas a la flexibilidad de la indigenidad (y no estrictamente los orígenes, papeles y número de los participantes en el equipo de realización ${ }^{11}$ y la función asignada a esto (al

11 En términos de descendencia, organización, colaboración, práctica, producción y distribución, el cine indígena se podría definir como "el número creciente de casos cuando los miembros de la comunidad han iniciado su propia producción cinematográfica, pero que se parece más a la producción de proyectos en video. En estos casos, se pueden involucrar antropólogos, para conseguir [fondos], equipamiento $u$ organizar la instrucción tecnológica o estudiar las películas o los casetes en el interior de los procesos locales de comunicación visual. La observación y el estudio se enfocan sobre las energías e cine) en la inscripción de una mirada particular de un tiempo y contexto especial, su operación en imágenes $\mathrm{y}$ visibilidades que puede asegurar, inscribir y educar nuevos posibles órdenes sensoriales para lograr sus fines políticos y no cuestiones marcadas por perspectivas convencionales sobre la calidad formal o profesional, modos antihegemónicos, alternativos de producción o las narrativas y poéticas posibilitadas por estas. Con razón, Fausto (2011) se pregunta críticamente desde esta perspectiva del esencialismo cultural si el tríptico de nuestro universo de valores - lo nuevo, lo auténtico y lo autorial- es la mejor herramienta para seguir leyendo e interpretando este tipo de producción cinematográfica.

La flexibilidad de los medios de estar en cualquier lado y cualquier tiempo, juntar (impensables) realidades, "simultaneando" el pasado y el presente, juntar lo desjuntable, separar lo inseparable, conduce a una gran reflexión, hacia la división de sí mismo y la unificación de la otredad. Intercambiando miradas a través de los medios les brinda a estos últimos propiedades mayéuticas cuando se

iniciativas locales ya existentes en el lugar y que operan con mínima ayuda de afuera" (Chalfen, 2007, p. 170). 
ve e imagina al otro y al sí mismo en el juego flexible, permeable, entre la semejanza y la otredad.

Es importante entender cómo el cine ${ }^{12}$ contribuye en la emergencia de nuevas prácticas y nuevas formas de producción cultural, las cuales, a su vez, están estimulando una reflexividad creciente entre la población local sobre qué significa ser indígena, y más precisamente indígena moderno en este comienzo de siglo. "Ver y conocer el mundo - de uno y del otro- a través de los medios electrónicos urge repensar las nociones establecidas sobre los medios y sus eficacias" (Deger, 2006, p. XIX).

Por otro lado, asociar el cine con lo indígena le brinda al primero nuevas valencias, posibilidades como arte y medio. Este acercamiento nos permite considerar el cine como un campo emancipatorio de intervención y participación (por su independencia de tecnologías complejas de captura

12 Desde esta postura, al cine en sí se le va a considerar su neutralidad, flexibilidad y desprendimiento de la dependencia del aparato (medium) de las recientes invenciones y evoluciones tecnológicas, las cuales de cierta manera han aumentado las formas y las posibilidades para experimentarlo (Casetti, 2001). El cine se va a liberar de alguna acusación de ideología inherente de mirada y poder, y se va a resaltar su apertura y flexibilidad para inscribir e inscribirse desde una presuposición de igualdad. y proyección, normativa de calidad y experticia), donde el sentido se puede despertar y educar, nuevos mundos posibles se pueden presentar y presenciar, las diferencias pueden convivir, las heterogeneidades se pueden enlazar. Tal cine (el estético) ${ }^{13}$ a su vez permite y posibilita un mundo sin jerarquías, donde cada parte tiene un igual estatus, donde lo "insignificante" deviene tan importante como lo "mitológico", donde el indio es tan visible y capaz como el blanco.

Otro aspecto de la declaración de Pinhata expresa su preocupación por "lo propio" frente a las tecnologías de fuera, donde "lo propio" define la etnia como siendo "menos" que la nación. Como brasileño (nación) se

13 La era estética (aesthetic age) redota al cine con el poder reflexivo para cuestionarse, descubrir y reconocer su otro "igual" dentro de sí, y la capacidad de ese "otro" para liberarse de la subordinación causada por la enmarcación de la mirada ideologizada y arreglo "legislativo" de la trama, cronología de eventos, narrativa progresiva, fines para seguir y proyectos para cumplir. En lugar del todo jerárquico y la subordinación de las partes bajo la organización inteligible, evolución lógica del relato, primacía de la trama y trayectoria conclusiva, el cine de la era estética enriquece el mundo sensible con el poder del pensamiento y del habla. Aquí "las poéticas de lo sensible que habla" (Tanke, 2011 1, p. 111 1) y"la prosa ordinaria del mundo [...] presencia íntima de las cosas y la verdad desnuda de la vida" (Rancière, 2006, p. 11 producen choques y continuidades con la (aristotélica) poética representativa de jerarquías, reglas y objetivos. 
puede usar de manera segura la tecnología, pero como ashaninka (etnia) existe el peligro de perder el "aura" (o recuperarla a través de la apropiación de los medios desde las prácticas y los discursos residuales).

La "supercultura" (Fausto, 2011) entendida como una imagen "propia" vista en el espejo ofrecido a los indígenas por el blanco está de cierta manera condenada a lo especial, remoto, ahistórico, separado, aislado, puro, "museomificado". El encuentro de la etnia con la tecnología atestigua una "cultura en movimiento"14, donde el uso "propio" y el sello cultural no significan aquí crear una media reservation (Roth, 2002), sino ser tratados como iguales en el encuentro, la posibilidad de manipular y devenir experto un dispositivo ajeno como cualquier otra persona, reconsiderar la presuposición de seres des-iguales (brasileño-ashaninka particularmente y nación-etnia generalmente) en cualquier encuentro con la otredad (aquí, la tecnología y su mirada).

14 La cultura designa aquí "maneras de ser [...] dentro de un rango de contextos extremadamente diversos, [...] un sistema milenario de continuidad y transformación" (Fausto, 2011 ) que no exluye lo contemporáneo.
Acceder a la otredad ${ }^{15}$ (o estar accedido por ella) no significa perder o perderse. La otredad podría resultar en un acto emancipatorio, abriendo nuevos campos de experiencia, posibilitando nuevas capacidades, reconfigurando la posición de uno hacia uno mismo y el mundo (Rancière, 2009).

El encuentro del indígena con sus imágenes, memorias, historia y cine (medios en general) ha producido resultados sorprendentes dentro de las sociedades nacionales a las cuales $^{16}$, atestiguando de manera esperanzadora que no existen expertos innatos, capacidades heredadas, papeles asignados ni "mentes frágiles" que

15 "El 'otro' está siempre designado por un sujeto, el cual para poder usar esta designación tiene que afirmarse como sujeto, como un lugar de habla, como un lugar desde el cual la mirada se origina. La afirmación de este sujeto como el centro es la propia negación del 'otro', del reconocimiento de su existencia, porque lo niega como el origen del habla y visión. [L]a filosofía de la "otredad" solo comienza cuando el sujeto que aplica la palabra 'otro' acepta que él o ella es un 'otro' si el centro se cambia, él o ella acepta ser un 'otro' para el 'otro'" (Bernardet, 20111.

16 Éxitos de taquilla como The whale rider (2003), Once were warriors (1994) de los maoríes de Nueva Zelanda, Smoking signals (1988) en los Estados Unidos, Atanarivat/ The fast runner (200 1) hablado en inuktitut de Isuma Productions en Canadá lel cual ganó un Caméra D'Or para la mejor película de debut en el Festival de Cine de Cannes), son algunos ejemplos por excelencia de tal encuentro. 
se van a afectar, manipular o perderse. Si se accede a la otredad desde una posición inferior, tímida, limitada, desconfiada, forzada, "protegida", lo que también puede ocurrir, es agrandar la experiencia social, ganar un surplus, devenir lugar de estar condenado a un ser eterno, programado, limitado de deseo latente, voluntad extinguida y victimización vitalicia.

Sin embargo, la "extrañeza" de la incompatibilidad del encuentro del indígena con los medios (el cine) aún persiste, perpetuando la ya mencionada invisibilidad histórica, reduciendo las lecturas de los "productos culturales" (aquí, películas) posicionadas en dos extremos.

Existe, por un lado, un entendimiento desde el "discurso universalista" y la circulación de los medios indígenas como el cine (entendido a su vez como arte e industria dentro de la lógica convencional) con un surplus de extrañeza y exotismo, que ignora los orígenes y las necesidades (de los realizadores y los productos) en un contexto local (Huhndorf, 2009), y por otro lado el papel medial altamente político relacionado con las "políticas de identidad" y las "políticas de reconocimiento" que surgen a través de la activación de la memoria, la recuperación cultural, la reclamación del territorio y los derechos sociales, dándoles a estos medios un aspecto oposicional, activista y cometido.

Un tercer espacio se va a abrir aquí para escapar de la trampa fácil de estos acercamientos en la relación de la indigenidad con los medios. Apropiarse de las tecnologías, imponer la autoridad y la autoría (en las autorrepresentaciones), inscribir la expresión cultural y alcanzar las audiencias (estratégicas) son las condiciones primarias, pero no últimas, para cumplir los objetivos políticos (comunales), “propios” (culturales), los cuales a su vez pueden ser comprometidos por otros factores determinantes $^{17}$ (Armes, 1995).

Los medios indígenas se discuten principalmente con estas suposiciones de tecnología (como apropiación de lo ajeno), autoridad y mediación como suficientes para cumplir los fines (ideologías) culturales respecto de textualidad o extratextualidad alrededor de las "políticas de identidad",

17 Tales como los modos de producción, discontinuidades en los procesos de formación y realización, factores de decisión, como los jefes, la comunidad, la naturaleza de coproducción, el entrenamiento y la experticia, aspectos de financiación, distintas agendas de las $\mathrm{ONG}$, agenda global indígena, agendas ocultas, relación con las diferentes audiencias y sistemas de visibilidad en los circuitos académicos o convencionales, censura interna y externa, etcétera. 
donde la naturaleza, la inscripción, el alcance, la operación (disensual) y el poder (estético) de la imagen se suponen, ignoran o simplemente desconocen. Desde esta perspectiva, la imagen en sí queda altamente "sociologizada", suponiendo que cumple su "misión" social por el simple hecho de ser una representación, o representación material, una semejanza de realidades moralmente intolerables sobre las cuales una autoría $y$ autoridad ética se ejerce.

... las imágenes cuentan más con la estetización que con la indignación. Más que presentándose como explicación sobre las fuentes de miseria, las imágenes localizan las capacidades escondidas, los poderes de habla y visión, y formas de relación que esquivan la distribución dominante de lo sensible ${ }^{18}$, afectando así la estésis (aesthesis) general (Tanke, 2011, p. 140).

18 La distribución de lo sensible lle partage du sensible) hace referencia a la ley implícita que gobierna el orden de lo sensible que otorga lugares y formas de participación en un mundo común, estableciendo primeramente los modos de percepción dentro del cual estos se inscriben" (Rockhill, 2004, p. 85), que, a su vez, definen las formas de inclusión y exclusión, las modalidades de lo visible y audible como también de lo que se puede decir, pensar o hacer, entendiendo lo sensible como lo que es capaz de ser aprehendido por los sentidos (Rancière, p. 2004).
La nueva indigenidad y el cine indígena emergente usan las capacidades de la imagen estética para suspender el propio sentido común y para intervenir el sentido común del otro común, considerando la identidad cultural como una categoría que no puede estar eternamente fijada, sino como algo que tiene que redistribuirse regularmente.

Los dilemas de tradición e innovación inevitablemente nos dejan sin una sola o definitiva respuesta. Nosotros mismos no seguimos más "deviniendo blancos", porque creemos que hemos devenido ya lo suficiente. Esta condición parece haberse logrado finalmente: tampoco necesitamos hacer cine europeo, cine hollywoodense, cine brasileño o cualquier nuevo cine. ¿No sería más generoso, entonces, desearles a los indios devenir indios a su manera, aun si esto significara "devenir blanco" una vez más? (Fausto, 2011, p. 238).

\section{Referencias bibliográficas} Alia, V. y Bull, S. (2005). Media and ethnic minorities. Edinburgo: Edinburgh University Press.

Armes, R. (1987). Third world film making and the west. Berkeley y Los 
Ángeles: University of California Press.

Aufderheide, P. (2000). The daily planet: a critic on the capitalist culture beat. Minneapolis: University of Minnesota Press.

Bernardet, J.-C. (2011). Video nas aldeias, documentary and "otherness". En Video nas aldeias 25 anos: 19862011. Olinda: Camara Brasilera do Livro.

Biesta, G. (2006). Beyond Learning: Democratic Education for a Human Future. Paradigm Publishers, PO Box 605, Herndon, VA 20172-0605.

Bingham, C. y Biesta, G. (2010). Jacques Rancière: education, truth, emancipation. Londres y Nueva York: Continuum International Publishing Group.

Cadena, M. de la y Starn, O. (eds.) (2007). Indigenous experience today. Berg: Oxford.

Casetti, F. (2001). Cinema lost and fund: trajectories of relocation. Recuperado de http://www.screeningthepast.com/2011/11/cinema-lost-andfound-trajectories-of-relocation/
Chalfen, R. (2007). The worth/adair navajo filmmaking experiment. En B. Engelbrecht (ed.), Memories of the origins of ethnographic film (pp. 16575). Fráncfort del Meno: Peter Lang.

Coates, K. S. (2004). A global history of indigenous peoples: struggle and survival. MacMillan: Palgrave.

Conklin, B. A. (1997). Body paint, feathers, and VCRs: aesthetics and authenticity in amazonian activism. American Ethnologist, 24(4), 711-737.

Corrêa, M. (2006). Video from the villages in video in the village exhibition: through the indian eyes. Recuperado de http://www.videonasaldeias.org.br/

Corrêa, M. (2006). Video nas aldeias from the other's viewpoint. Recuperado de http://www.videonasaldeias. org.br/

Deger, J. (2006). Shimmering screens: making media in an aboriginal community. Minneapolis: University of Minnesota Press.

Díaz-Polanco, H. (2000). Los dilemas de la diversidad. Diálogos Latinoamericanos, 2, 77-91. 
Fausto, C. (2006). Cultural by addition: an indigenization of technology? Paper for the roundtable on ' $\mathrm{Pu}$ blic Policies for Indigenous Cultural Production', Video nas Aldeias Film Expo, Um Olhar Indígena. Centro Cultural Brasil-Espanha, Brasilia.

Fausto, C.(2011). Registering culture: the smell of the whites and the cinema of the Indians. En Video nas aldeias 25 anos: 1986-2011. Olind: Camara Brasilera do Livro.

Ginsburg, F. D. (2003). Screen memories and entangled technologies: resignifying indigenous lives. En E. Shohat y R. Stand (eds.), Multiculturalism, postcoloniality, and transnational media (pp. 77-98). Piscataway, NJ: Rutgers University Press.

Ginsburg, F. D. (1991). Indigenous media: faustian contract or global village? Cultural Anthropology, 6(1), 92-112.

Ginsburg, F. D. (1994). Embedded Aesthetics: creating a discursive space for indigenous media. Cultural Anrhropology, 9(3), 365-382.

Ginsburg, F. D. (2002). Screen memories: resignifying the traditional in indigenous media. En F. D. Ginsburg,
D. L. Abu-Lughod y B. Larkin (eds.), Media worlds: anthropology on new terrain (pp. 39-57). Berkeley, Los Ángeles y Londres: University of California Press.

Ginsburg, F. D. y Myers, F. (2006). A history of aboriginal futures. Critiques of Anthropology, 26(1), 27-45.

Guha, R. (1989). Radical american environmentalistm and wilderness preservation: a third world critique. Environmental Ethics, 11(1), 71-83.

Himpele, J. (2004, junio). Packaging Indigenous media: an interview with Ivan Sanjinés and Jesús Tapia. American Anthropologist, 106(2), 354-363.

Himpele, J. D. (2008). Circuits of culture: media, politics and indigenous identity in the Andes. Minneapolis y Londres: University of Minnesota Press.

Huhndorf, S. M. (2009). Mapping the Americas: the transnational politics of contemporary native culture. Ithaca y Londres: Cornell University Press.

Knopf, K. (2008). Decolonizing the lens of power. Ámsterdam y Nueva York: Rodopi. 
Manevy, A. (2011). Powerful images of the villages. En Video nas aldeias 25 anos: 1986-2011. Olinda: Camera Brasilera do Livro.

Miller, B. G. (2003). Invisible indigenes: the politics of nonrecognition. Lincoln y Londres. University of $\mathrm{Ne}-$ braska Press.

Nilsson-Julien, O. (2005). Significant Others and possible selves: political myths, historytelling and social identity in Québécois Cinema, 19801995. Bayreuth. Tesis de doctorado, Universität Bayreuth.

Pinhanta, Isaac, Ashaninka filmmaker and teacher, interview in "Tratado de alteridade" - Cinestesia.

Poole, D. (1997). Vision, Race, and Modernity: A Visual economy of the Andean Image World. Princeton, New Jersey: Princeton University Press.

Pratt, M. L. (2007). Imperial eyes: travel writing and transculturation (2. ${ }^{\mathrm{a}}$ ed.). Nueva York: Routledge.

Ramos, A. R. (1998). Indigenism: ethnic politics in Brazil. Wisconsin: University of Wisconsin Press.
Rancière, J. (1995). La mésentente: politique et philosophie. Editions Galilée.

Rancière, J. (2009). The emancipated spectator (trad. G. Elliot). Londres y Nueva York: Verso.

Rancière, J. (2004). The politics of aesthetics: the distribution of the sensible (trad. e introd. G. Rockhill). Londres y Nueva York: Continuum.

Rancière, J. (2006). Film fables (trad. E. Battista). Oxford y Nueva York: Berg.

Rancière, J. (2007). The future of the image (trad. G. Elliott). Londres y Nueva York: Verso.

Rancière, J. (2009). Aesthetics and its discontents (trad. S. Corcoran). Cambridge UK y Malden, USA: Polity.

Rancière, J. (2011). The thinking of dissensus: politics and aesthetics. En P. Bowman y R. Stamp (eds.), Reading Ranciére. Nueva York: Continuum.

Rockhill, G. (2004). Glossary of Technical Terms. En R. Jacques, The politics of aesthetics: the distribution of the sensible (trad. e introd. G. Rockhill). Londres y Nueva York: Continuum. 
Roth, L. (2002). Something New in the Air: Indigenous Television in Canada, Montreal: McGill Queens University Press.

Ruby, J. (1991). Speaking for, speaking about, speaking with, or speaking alongside - an anthropological and documentary dilemma. Visual Anthropology Review, 7(2), 50-67.

Salazar, J. F. y Córdova, A. (2008). Imperfect media and the poetics of indigenous video in Latin America. En P. Wilson y Stewart, M. (eds.), Global indigenous media: cultures, poetics and politics. Durham, North Carolina: Duke University Press.

Schiwy, F. (2009). Indianizing film: decolonization, the Andes, and the question of technology. New Brunswick, Nueva Jersey y Londres: Rutgers University Press.

Sturken, M. y Cartwright, L. (2009). Practices of looking: an introduction to visual culture (2. ${ }^{\mathrm{a}}$ ed.). Nueva York y Oxford: Oxford University Press.

Tanke, J. J. (2011). Jacques Rancière: an introduction philosophy, politics, aesthetics. Londres y Nueva York: Continuum.

Turner, T. (2002). Representation, politics, and cultural imagination. En Indigenous video: general points and kayapo examples (pp. 75-89).

Worth, S. y Adair, J. (1973). Through Navajo Eyes. Bloomington: University of Indiana Press.

Zamorano, G. (2009). Reimagining politics: Video and indigenous struggles in contemporary Bolivia. Nueva York. Tesis de doctorado, The City University of New York. 